www.jmscr.igmpublication.org

Index Copernicus Value: 79.54

ISSN (e)-2347-176x ISSN (p) 2455-0450

crossrefDOI: https://dx.doi.org/10.18535/jmscr/v7i3.56

\title{
Correlation between Severity of Microalbuminuria with HbA1c in type II Diabetic Patients
}

\author{
Authors \\ Dr Deepasha Shahi Bagzai (Asst. Prof.), Dr Avinash Bagzai* \\ *Corresponding Author \\ Dr Avinash Bagzai
}

\begin{abstract}
Introduction: Type 2 Diabetes is now a a gloabal endemic and the prevalence is ever increasing with socio economic changes, more geriatric population, urbanisation, dietary changes, less physical exercise and lifestyle changes. The risk of developing microvascular complications increases wit duration and severitity of diabetes. So through this study we tried to explore the relationship between severity of diabetes with development of microalbuminuria.

Material \& Methods: A total of 472 patients with known history of type 2 Diabetes mellitus attending almology OPD of hospital were for enrolled for the study. The study is a cross sectional study.

The cases were subjected to detailed medical and examination after noting their detailed medical and demographic history. All patients were investigated for serum creatinine, serum urea, fasting or postprandial blood sugar levels, HbAlc levels and urine microalbumin levels.

Results: Of the total 472 cases there were 261 males and 211 females, so the female: male ratio was 0.8:1.The majority of the patients lie in age group of 41 to 60 years. Patient were divided in 4 groups depending on the levels of microalbuminuria and most patients with significant data.

Conclusion: There was a statistical significant correlation between the severity of microalbuminuria and diabetes duration. Also statistically significant Association was found between HB alc values and severity of microalbuminuria.
\end{abstract}

Keywords: HbAlc, diabetes duration, microalbuminuria.

\section{Introduction}

Diabetes mellitus (DM) is a group of metabolic disorders that results in hyperglycemia because of defects in insulin secretion or its action or both ${ }^{[1]}$. It is emerging as a global endemic both in developing and developed countries ${ }^{[2]}$. It is characterized by recurrent or persistent hyperglycemia, and is diagnosed by demonstrating any one of the following: fasting blood sugar (FBS) level at or above $126 \mathrm{mg} / \mathrm{dL}$, plasma glucose at or above $200 \mathrm{mg} / \mathrm{dl}$ two hours after a 75 $\mathrm{g}$ oral glucose load as in a glucose tolerance test (GTT), random plasma glucose at or above 200 $\mathrm{mg} / \mathrm{dl}$, (WHO report, 2006) ${ }^{[3]}$. The prevalence of diabetes in India is found to be $2.4 \%$ in rural and $4-11.6 \%$ in urban population ${ }^{[4]}$.

Glycosylated hemoglobin (HbA1c) is a commonly used marker for determining long-term control of blood sugar. The HbA1c test is done every 3 to 4 months, and unlike blood sugar levels, the test 
does not change with any recent changes in diet, exercise or medicines ${ }^{[5]}$. Higher levels, indicating poorer control of blood glucose have been associated with cardiovascular disease, nephropathy \& retinopathy ${ }^{[6]}$. The HbA1c assay is the basis of treatment guidelines and is used universally to adjust therapy ${ }^{[7,8]}$.

Microvascular complications are very common in diabetes, diabetic retinopathy being the most common. ${ }^{[9]}$ The common microvascular complication associated with diabetes is diabetic nephropathy. Microalbuminuria is defined as albumin excretion of 30-299 $\mathrm{mg} / 24$ hours. Microalbuminuria term was $1^{\text {st }}$ coined by Professor Harry Keen in 1964.

The association between two major microvascular complications of diabetes (nephropathy and retinopathy) has been explored and results have shown a direct corelationship between the two ${ }^{[5-7]}$. Through this study we tried to correlate the degree of severity of microalbuminuria with its diabetes duration and level of hyperglycemia.

This was an outpatient based cross-sectional study in which 472 consecutive patients with known history of type 2 Diabetes mellitus, who attended the outpatient department of medicine or diabetes OPD were enrolled. After a detailed demographic and medical history recording a detailed examination was performed in a preset proforma. Exclusion criteria included patients with gestational diabetes, acute or chronic Kidney Disease, cancer, coronary artery disease, and coexisting conditions like fever, systemic infections, malignant hypertension or congestive cardiac failure. Blood samples were collected after
10 hours of fasting and Vitros 5,1 FS machine was used for testing $\mathrm{HbAlc}$ (estimated by turbidimetric innovation method).

Microalbuminuria levels were measured for all patients by $\mathrm{Hb}$ Vario (high performance liquid chromatography). Chi square test was used to analyse the data and $p$ value of 0.05 or less was considered to be significant.

\section{Results}

Out of the total 472 patients registered in the study, there were 261 males and 211 females. The female to male ratio was $0.8: 1$. Majority of the patients were in the age group of 41 to 60 years (54.87\%) followed by 61 to 80 years ( $25.63 \%$ ) with mean age being $54.43 \pm 7.56$ years. (Table 1)

Table 1 Demographic distribution of study population

\begin{tabular}{|c|c|c|}
\hline & No. of cases & Percentage \\
\hline Male & 261 & 55.29 \\
\hline Female & 211 & 44.71 \\
\hline \multicolumn{3}{|c|}{ Age group ( years ) } \\
\hline $20-40$ & 62 & 13.13 \\
\hline $21-40$ & 259 & 54.87 \\
\hline $61-80$ & 121 & 25.63 \\
\hline$>80$ & 30 & 6.35 \\
\hline
\end{tabular}

Out of 472 patinets were divided in 4 groups , group1 containing patients with microalbumin levels less than $2.5 \mathrm{mg} / \mathrm{mmol}$, group 2 had patients with level between 2.5 to $12.5 \mathrm{mg} / \mathrm{mol}$, group 3 with levels between 12.5 to $25 \mathrm{mg} / \mathrm{mmol}$ and group34 had patients with microalbuminuria levels more than $25 \mathrm{mg} / \mathrm{mol}$.The duration of diabetes was significantly correlated with the degree of microalbuminuria $\mathrm{p}<0.05$.

\section{Table 2}

\begin{tabular}{|l|c|c|c|c|c|c|c|c|c|}
\hline & & \multicolumn{2}{|c|}{ Group I } & \multicolumn{2}{|c|}{ Group 2 } & \multicolumn{2}{|c|}{ Group 2 } & \multicolumn{2}{c|}{ Group 3 } \\
\hline $\begin{array}{l}\text { Duration Of } \\
\text { Diabetes } \\
\text { (Years) }\end{array}$ & $\mathrm{N}=$ & No. & $\%$ & No. & $\%$ & No. & $\%$ & No. & $\%$ \\
\hline & & 262 & 55.50 & 78 & 16.52 & 62 & 13.13 & 70 & 14.83 \\
\hline$<10$ years & 218 & 172 & 78.8990826 & 31 & 14.22018 & 13 & 5.96330275 & 2 & 0.91743119 \\
\hline $10-20$ years & 141 & 76 & 53.9007092 & 22 & 15.60284 & 19 & 13.4751773 & 24 & 17.0212766 \\
\hline $21-40$ years & 84 & 10 & 11.9047619 & 20 & 23.80952 & 21 & 25 & 33 & 39.2857143 \\
\hline$>40$ years & 29 & 4 & 13.7931034 & 5 & 17.24138 & 9 & 31.0344828 & 11 & 37.9310345 \\
\hline
\end{tabular}


Severity of hyperglycemia was graded according to HbA1c levels. Values less than $7 \%$ were considered to be good control of diabetes. Levels between 7.1 to $8.5 \%$ - fair control and levels beyond $8.5 \%$ were considered to be in poor control.

Table 3 shows that the prevalence of microalbuminuria is less among patients with good control of diabetes, with only $1.17 \%$ paient having clinically significant microalbuminuria as compared to those with fair $(29.1 \%)$ or poor control $(941.3 \%)$ of diabetes. A statistically significant association between severity of microalbuminuria and $\mathrm{HbA} 1 \mathrm{c}$ values was Found $(\mathrm{p}<0.001)$ (Table 3).

Table 3

\begin{tabular}{|l|c|c|c|c|c|c|c|c|c|}
\hline Hba1c & & \multicolumn{2}{|c|}{ Group I } & \multicolumn{2}{c|}{ Group 2 } & \multicolumn{2}{c|}{ Group 2 } & Group 3 \\
\hline & $\mathbf{n}=$ & No. & \% & No. & \% & No. & \% & No. & \% \\
\hline Good control (<-7.0\%) & 256 & 190 & 74.21875 & 56 & 21.875 & 7 & 2.734375 & 3 & 1.171875 \\
\hline Fair control (7.1-8.5\%) & 158 & 41 & 25.94937 & 38 & 24.05063 & 33 & 20.88608 & 46 & 29.11392 \\
\hline Poor control (>8.5\%) & 58 & 5 & 8.62068966 & 13 & 22.41379 & 16 & 27.58621 & 24 & 41.37931 \\
\hline
\end{tabular}

\section{Discussion}

The prevalence of type $2 \mathrm{DM}$ is estimated to double by $2030^{[12]}$. Diabetes is known to be associated with both microvascular and macrovascular complications, including retinopathy, nephropathy, and neuropathy (microvascular) and ischemic heart disease, peripheral vascular disease, and cerebrovascular disease (macrovascular), resulting in organ and tissue damage in approximately one third to one half of people with diabetes ${ }^{[10]}$ the higher the degree of diabetes, the more likely are the chances to develop theses complications

In our study, we found that most of patients who have microalbuminuria had fair $(63 \%)$ to poor (32\%) control of diabetes mellitus, or the duration of diabetes is 20 years or more in most $(62.85 \%)$ of them.. Another Indian study have got the same results and concuded that Level of microalbuminuria increase with increase in duration of diabetes and worsening of diabetes ${ }^{[11]}$ .Other cross-sectional studies, also shows that the prevalence of microalbuminuria is related with poor glycemic control. ${ }^{[13-16]}$

Our study stresses on the relationship between the control level of type 2 diabetes mellitus and microalbuminuria. It was seen that higher grades of $\mathrm{HbA1c}$ is associated with higher severity of microalbuminuria and so can be used as a successful predictor and warning for such patients as this high level has been correlated with many other microvascular complications of diabetes.. Our study was limited by time, so a better knowledge of this relationship could be collected with the help of more longer longitudinal clinical trials with new type 2 diabetic patients.

\section{Conclusion}

The results of our study endorses and strengthen the view that higher levels of $\mathrm{HbA} 1 \mathrm{c}$ is associated with greater risk and severity of development of microalbuminuria and its control is essential to prevent other microvascular complications of diabetes.

\section{References}

1. Ratnamanjulasonga, siddhartha.k, dr. sudhakar.k research article "lipid profile in type 2 diabetes mellitus with obesity" bulletin of pharmaceutical and medical sciences (bopams) vol.1.issue.2.;2013.

2. Prabhavathi K., KirthanaKunikullaya U., and Jaisri Goturu Glycosylated Haemoglobin (HbA1c) - A Marker of Circulating Lipids in Type 2 Diabetic Patients J ClinDiagn Res. Feb 2014; 8(2): 20-23. 
3. Definition and Diagnosis of Diabetes mellitus and hyperglycemia. Report of a WHO / IDFC consultation, Geneva WHO, 2006

4. WHO. 1998. Prevention and control of Diabetes Mellitus, Report of an Intercountry workshop, Dhaka, Bangladesh, 2730 April 1998, SEA/NCD/40.

5. Ram Vinod et al ;Association between glycemic control and serum lipid profile in type 2 diabetic patients : glycated haemoglobin as a dual marker ; Biomedical research 2011;22(3) : 375-380

6. Sibley SD, Thomas W, de Boer I, Brunzell JD, Steffes. Gender and elevated albumin excretion in the MW Diabetes Control and Complications trial/ Epidemiology of Diabetes Interventions and Complications (DCCT/EDIC) cohort: role of central obesity. Am J Kidney Dis 2006; 47:223232.

7. American Diabetes Association, Diabetes Care 2007,30,S4-S41

8. Nathan, D.M., Buse, J.B., Davidson, M.B., Heine, R.J., Holman, R.R.,Sherwin, R., Zinman, B., Diabetelogia 2006,49,17111721.

9. Fong DS, Aiello LP, FL: Diabetic Retinopathy. Diabetes care 2004; 27: 2540-2553.

10. UK Prospective Diabetes Study Group. Intensive blood glucose control with sulphonylureas or insulin compared with conventional treatment and risk of complications in patients with type 2 diabetes (UKPDS33). Lancet 1998; 352: 837-853

11. Correlation of microalbuminuria with glycosylated haemoglobin in patients of diabetes having nephropathy Mayank Gupta*, Jagat Pal Singh DOI: http://dx.doi.org/10.18203/2349-

3933.ijam20172276
12. Cade WT et al. Diabetes-Related Microvascular and Macrovascular Diseases in the Physical Therapy Setting. Phys Ther. Nov 2008; 88(11): 1322-1335

13. Baig JA, Asif N, Sarfaraz A, Alam JM. Correlation of microalbuminuria with glycosylated hemoglobin (Hbalc) and duration of type 2 diabetes mellitus (T2DM) in male and female patients. Middle-East J Sci Res. 2016;24(9):2900-3.

14. Raman S, Dai H, DeLurgio SA, Williams DD, Lind $M$, Patton SR, et al. High hemoglobin A1c variability is associated with early risk of microalbuminuria in children with T1D. Pediatr Diabetes. 2016;17(6):398-406

15. Ichinose K, Kawasaki E, Eguchi K. Recent advancement of understanding pathogenesis of type I diabetes and potential relevance to diabetic nephropathy. Am J Nephrol 2007; 27: 554-564.

16. Singh DK, Winocour P, Farrington K. Mechanisms of disease: the hypoxic tubular hypothesis of diabetic nephropathy. Nat Clin Pract Nephrol 2008; 4: 216-226. 